\title{
O PAPEL DA TRADUÇÃO INTERSEMIÓTICA PARA A LEGENDAGEM DE SÉRIES: ANALISANDO AS FALAS DE LADY VIOLET NA 1T DE DOWNTON ABBEY
}

\author{
Rossana Luna 1 \\ Sinara de Oliveira Branco 1 \\ 1-Universidade Federal de Campina Grande, Campina Grande, Paraíba, Brasil
}

\begin{abstract}
Resumo: Buscando contribuir para as práticas de legendagem, este artigo é um recorte de uma pesquisa desenvolvida no Programa de PósGraduação em Linguagem e Ensino da Universidade Federal de Campina Grande. O estudo analisa a influência da Tradução Intersemiótica sobre a legendagem de falas da personagem Lady Violet Crawley, na série Downton Abbey. Como referencial teórico, utilizamos discussões sobre Tradução Intersemiótica de Plaza (2013), Jakobson (2000) e Frías (2011); de Semiótica de Pignatari (2004) e Pierce (2005); de legendagem por Georgakopoulou (2009), Betz (2009) e Skuggevik (2009); além de estudos sobre a face e expressões faciais como sistema de sinais de Ekman e Friesen (2003) e Darwin (1872), entre outros. Este estudo se insere dentro dos Estudos de Tradução de Multimídia (Williams; Chesterman, 2002), sendo orientado pelo produto. Os resultados indicam que a tradução intersemiótica gera legendas que são influenciadas, compensadas e/ou complementadas pelo não-verbal em reflexão de estratégias de legendagem que respeitam o quadro semiótico da obra.
\end{abstract}

Palavras-chave: Tradução Intersemiótica; Legendagem; Downton Abbey

\section{THE ROLE OF INTERSEMITIC TRANSLATION FOR SERIES LEGENDING: ANALYZING LIKE LADY VIOLET SPEAKERS IN DOWNTON ABBEY 1T}

Abstract: To contribute to the subtitling practices, this paper presents part of a research that was carried out in the Programa de Pós-Graduação em Linguagem e Ensino of the Universidade Federal de Campina Grande. 
The study analyzes the influence of Intersemiotic Translation on the subtitling of Lady Violet Crawley's lines in Downton Abbey. As theoretical reference, we use discussions about Intersemiotic Translation by Plaza (2013), Jakobson (2000) and Frías (2011); of Semiotics by Pignatari (2004) and Pierce (2005); of subtitling by Georgakopoulou (2009), Betz (2009) and Skuggevik (2009); as well as studies on facial expressions by Ekman and Friesen (2003) and Darwin (1872), among others. This study is part of Multimedia Translation Studies (Williams; Chesterman, 2002), and it is product-oriented. Results indicate that Intersemiotic Translation generates subtitles that are influenced, compensated and/or complemented by the non-verbal elements of the film and derivates subtitling strategies that respect the semiotic framework of the audiovisual piece.

Keywords: Intersemiotic Translation; Subtitling; Downton Abbey

\section{Introdução}

Um dos campos da tradução que permite o consumo de filmes estrangeiros no Brasil é o da legendagem, em que se mantém o áudio original do filme e o processo de transferência linguística se dá pela transposição do fato verbal-oral fílmico para um texto escrito, posteriormente adicionado à tela (Cintas; Anderman, 2009). Georgakopoulou (2009) defende a qualidade das legendas em função da sua invisibilidade. Entretanto, a legenda é um elemento de interferência adicionado na pós-produção do filme de forma terceirizada (Gorovitz, 2015). Em virtude disso, devemos refletir o que é a "invisibilidade" em legendagem, concebendo, por exemplo, legendas "invisíveis" como aquelas que não chamam a atenção do telespectador desviando sua atenção da imagem.

Para tanto, as legendas devem buscar ter uma legibilidade fruto da coesão entre os três elementos formativos dos programas legendados: a palavra falada, a imagem e as legendas (Cintas; Ramael, 2014). Nesse contexto, uma das competências necessárias ao legendador é a apresentada por Skuggevik (2009): compreender a dimensão psicológica e emocional que acompanha o diálogo. Esses aspectos não são inferidos apenas pelos diálogos dos produtos fílmicos, pois também dependem da linguagem não-verbal que constitui a cena. Dessa 
forma, o legendador deve ser também um tradutor intersemiótico, já que o ser humano é “fisiologicamente 'afinado' para distinguir entre harmonia e desarmonia” (Weil; Tompakow, 1986, p. 58).

Entre os produtos fílmicos estrangeiros importados pelo Brasil está a série Downton Abbey (2010 - 2015), que retrata a vida da aristocrata família Crawley e dos funcionários da propriedade que dá o nome à série, situada entre os anos de 1912 e 1925, mostrando como seus habitantes lidam com eventos históricos e a sociedade em que vivem. Na série, criada por Julian Fellowes, o público é apresentado a Lady Violet, a tradicional Condessa Matriarca de Grantham, de língua ferina e discurso sagaz. Considerando a noção de invisibilidade das legendas e a influência da imagem para que tal feito seja alcançado, propomo-nos a considerar a influência da Tradução Intersemiótica (TI) para o processo de legendagem de falas da personagem Lady Violet Crawley, na série Downton Abbey $(D A)$.

Buscando contribuir para as práticas vigentes de legendagem, este artigo é um recorte de uma pesquisa desenvolvida no Programa de Pós-Graduação em Linguagem e Ensino ${ }^{1}$ da Universidade Federal de Campina Grande e ratifica a necessidade de refletir crítica-analiticamente sobre a linguagem não-verbal, e como essa pode intervir sobre o processo tradutório audiovisual. Dentro das áreas de Estudos de Tradução mapeadas por Williams e Chesterman (2002), este artigo se enquadra entre as pesquisas descritas como Tradução de Multimídia, analisando textos audiovisuais. Investigações de Tradução de Multimídia podem se voltar para dublagem ou legendagem, este estudo volta-se à Legendagem.

Apresentamos, a seguir, o arcabouço teórico deste estudo.

\section{Traduzindo o verbal pelo não-verbal}

Jakobson (2000) propõe três maneiras de interpretar um signo verbal: a Tradução Intralingual, a Tradução Interlingual e a Tradu-

\footnotetext{
${ }^{1}$ Agradeço o apoio da CAPES e da Fulbright, representado pelas bolsas de estudo concedidas no período de março a maio de 2017 (CAPES); agosto de 2017 a junho de 2018 (Fulbright) e julho a dezembro de 2018 (CAPES).
}

Cad. Trad., Florianópolis, v. 39, no 3, p. 132-155, set-dez, 2019. 
ção Intersemiótica. A primeira é a operação pela qual se interpreta um signo verbal através de outros signos verbais da mesma língua. Já a segunda abrange o processo de interpretação de signos verbais de uma língua por meio de signos verbais em outra língua. Por fim, a última consiste na interpretação de signos verbais por intermédio de sistemas de signos não-verbais ou vice-versa.

Essas três categorias de tradução jakobsonianas trabalham em mutualismo, sendo inconcebível realizar uma tradução que envolva exclusivamente uma delas. Frías (2011) e Poyatos (1983) advogam a linguagem verbal como não autônoma, visto que a atribuição do significado total das palavras depende da linguagem não-verbal. A partir dessas considerações, asseveramos que antes de traduzir interlingualmente um produto cultural fílmico, o legendador precisa traduzir intersemioticamente esse produto. Portanto, precisamos discutir pontos da Semiótica e da natureza dos signos para entendermos como é que eles se configuram como suporte de pensamento.

\subsection{A linguagem não-verbal à luz da segunda tricotomia peirceana dos signos}

A Semiótica é a doutrina dos signos (Peirce, 2005). Um signo é algo que representa alguma coisa para alguém, criando na mente dessa pessoa um signo equivalente e/ou mais desenvolvido, alcunhado de interpretante. Para o autor, signos são divisíveis conforme três tricotomias cujos vértices de origem são (a) a qualidade do signo, (b) objeto do signo e (c) o interpretante do signo. Peirce (2005) atribui um valor superior à segunda tricotomia, que, em virtude das necessidades analíticas do corpus estudado neste artigo, discutiremos em mais detalhes.

A segunda tricotomia separa os signos em ícones, índices e símbolos (Peirce, 2015). Os ícones remetem-se aos objetos que denotam em virtude das características que são compartilhadas com o objeto (existente ou não), tais como equações algébricas ou desenho de uma estátua. $\mathrm{O}$ índice relaciona-se com o objeto que denota por uma conexão pautada no fato de que o índice é modificado 
pelo objeto, enquanto o objeto é modificado pelo índice, e.g.: um uniforme é exemplo de índice, pois uma indumentária dentro de um imaginário social nos remete a uma determinada profissão, ao mesmo tempo que a indumentária é circunscrita pela profissão.

Concluindo a segunda tricotomia, o símbolo associa-se ao objeto que denota em virtude de uma lei ou hábito, gerada comumente por uma associação de ideias gerais, que operam no sentido de fazer com que o símbolo seja interpretado como se referindo àquele objeto (Peirce, 2005). Portanto, o símbolo é uma convenção que conecta objeto e interpretação. Símbolos são criados a partir de pensamentos que envolvem conceitos, cujo significado cresce ao ser disseminado entre a população. Exemplos de símbolos são bandeiras e signos utilizados na linguagem não-verbal cinésica, como argumentaremos adiante.

A compreensão da segunda tricotomia dos signos é necessária para a análise da dimensão visual de uma cena fílmica, a fim de entender o peso do contexto codificado no signo para a legendagem. Afinal, imagens expressam em uma organização lógica e dialética e que se refletirá na linguagem verbal, tanto do texto-fonte, falas dos personagens, quanto do texto-produto, neste caso, legendas.

De acordo com Metz (1968), a imagem-plano é a unidade básica de uma obra fílmica. O autor ainda afirma que o plano sempre equivale a uma frase. A partir dessa afirmação, admitimos que cada plano-frase é um sintagma, que, por sua vez, é atravessado por eixos paradigmáticos-palavra, que são: número de personagens (e suas linguagens corporais), props $^{2}$, figurino, iluminação - todos esses elementos em conjunto formam a frase a ser apreendida e, portanto, neles precisamos reconhecer uma intenção informativa codificada estética-logicamente. Para este artigo, analisaremos a aplicação da Tradução Intersemiótica no eixo da expressão facial da atriz (eixo EFA) à luz da tricotomia peirceana, relacionando-a com o produto das legendas.

${ }^{2}$ De acordo com o Oxford Living Dictionaries, "props" são objetos portáteis, com excepção de mobiliário e fantasias, utilizados em peças de teatro ou filmes. PROP: In: OXFORD Living Dictionaries. Disponível em: < https://en.oxforddictionaries. com/definition/prop > . Acesso em 12 mai. 2017. 
Ekman e Friesen (2003) compreendem que a face é um sistema que exibe mais de um tipo de sinal ao transmitir uma mensagem. Para os autores, esse sistema transmite três tipos de sinais: estático (como a cor da pele), lento (v. g., marcas de expressão) e rápidos (a exemplo do erguer de uma sobrancelha). Através desse sistema, a face nos conduz à diferentes mensagens sobre emoção, etnia, idade, sexo, etc. Dentre esses três tipos de sinais faciais, os sinais rápidos transmitem mensagens emblemáticas. Ekman e Friesen (2003) utilizam o termo "emblema" para descrever signos de mensagens específicas. Os autores propõem que emblemas são equivalentes não-verbais de uma palavra ou frase. Isto é, relacionando o que sabemos sobre expressões faciais à descrição da tipologia dos signos de Peirce (2015), acreditamos que expressões faciais são utilizadas pelos atores como símbolos, pois a necessidade vocacional requer que ao encarnar a vivência de um personagem, esses profissionais garantam a compreensão das expressões faciais assinaladas a uma determinada emoção dentro de um quadro de diagrama facial.

A instrumentalização da habilidade em reconhecer os símbolos-diagrama-facial feita pelos autores preenche uma lacuna de conhecimento que pode se passar despercebida, porque, a leitura das expressões faciais não é uma habilidade inata ao ser humano (Ekman; Friesen, 2003). O nosso repertório mental de expressões faciais e que emoção elas demonstram é construído ao longo da vida. Assim, o legendador trabalha em uma constante tensão entre a amplitude do seu repertório pessoal de expressões faciais e o repertório pessoal dos telespectadores.

\section{A codificação lógica do plano-frase: abordagem para a leitura do verbal em conjunto ao não-verbal}

\subsection{Sistematizando a Série: $D A$ como Dados}

Para a seleção de cenas que formaram o corpus foram definidos os seguintes critérios: 1) a cena deve apresentar a personagem 
Lady Violet; 2) a cena deve proporcionar um acesso privilegiado à linguagem não-verbal empregada pela atriz, especialmente a face. Como o escopo deste artigo é a tradução das falas da personagem, Lady Violet, em comparação à representação imagética dessa personagem, a adequação do conteúdo aos critérios propostos prevalece sobre as questões de tamanho do corpus.

Ao todo, selecionamos seis cenas, capturadas pelo Bandicam, um software utilitário de captura de tela que possibilita tirar screenshots e/ou registrar mudanças de tela (imagem em movimento), armazenando esses dados no computador, mantendo a qualidade da imagem e adicionando uma marca d'água onde se lê o site para download do software. Não foi preciso alterar as configurações originais de gravação do software, cuja interface pode ser vista abaixo:

Imagem 1 - Interface do Bandicam
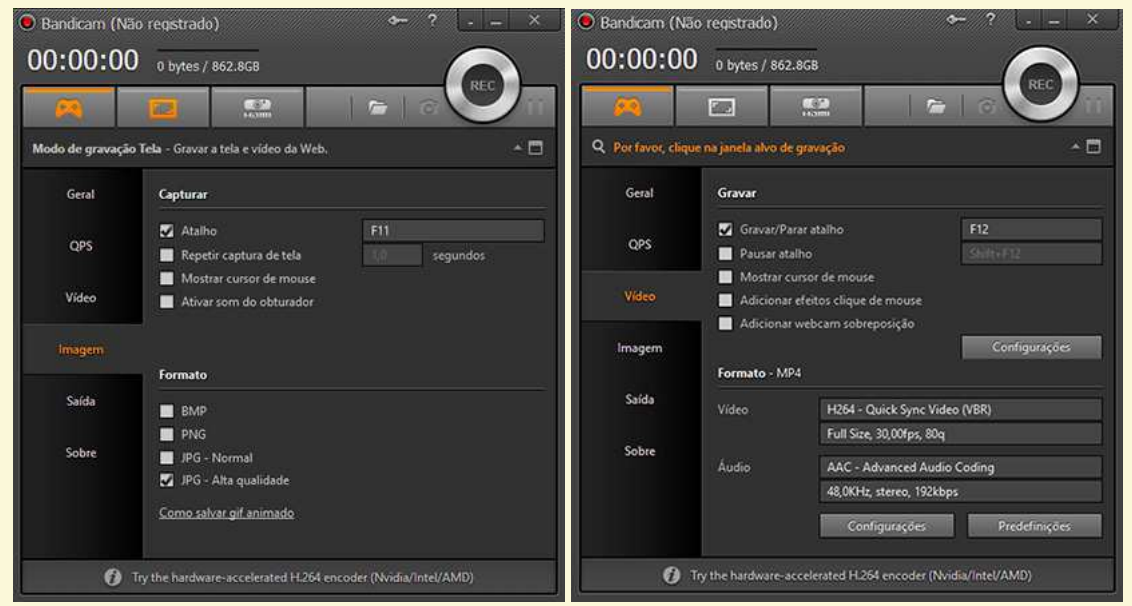

Fonte: Bandisoft

Utilizamos o Bandicam também para compilar screenshots das cenas selecionadas: a primeira cena resultou em 568 imagens; a segunda, em 77 imagens; a terceira em 102 imagens; a quarta, 46 ima- 
gens; a quinta, 646 imagens; a sétima, 134 imagens; a oitava, 175 imagens; e, da nona cena, acumulamos 85 imagens. Essas imagens nos auxiliaram na análise minuciosa das emoções na face da atriz.

\subsection{Procedimentos Metodológicos}

Os procedimentos metodológicos elencados para alcançarmos os objetivos propostos foram:

a. Assistir a $1 \mathrm{~T}$ da série $D A$ e catalogar as cenas em que Lady Violet aparece.

b. Identificar na $1 \mathrm{~T}$ da série $D A$ cenas em que a personagem Lady Violet é apresentada de acordo com os critérios propostos anteriormente.

c. Capturar as cenas utilizando o Bandicam.

d. Gerar um segundo registro das cenas por meio do recurso de captura de imagens congeladas do Bandicam.

e. Organizar o corpus pelo/a: (i) transcrição das falas, especificação do tempo (hora, minuto e segundos) em que cada fala aparece no decorrer do episódio e documentação da tradução das mesmas em quadros com linhas etiquetadas (seguindo o número da temporada e o número do episódio); (iii) seleção de imagens que demonstrem a linguagem facial da atriz em cena durante a performance do diálogo e inserção das mesmas abaixo dos quadros.

f. Leitura do livro Downton Abbey: The Complete Scripts Season One, de Julian Fellowes, que apresenta os scripts de filmagem e os comentários do criador, a fim de apurar a precisão da transcrição das falas de Lady Violet. 
g. Estudo dos diagramas faciais para a leitura de emoções e melhor direcionamento da interpretação do eixo EFA.

\subsection{Diagramas Faciais para Leitura das Emoções}

Para a leitura da linguagem não-verbal empregada pela intérprete de Lady Violet, consideramos os diagramas faciais delineados nos quadros abaixo, que trazem a descrição dos movimentos que podem constituir os diagramas faciais para surpresa, medo, nojo, presunção (Ekman; Friesen, 2003); além de reflexão/meditação, desdém/desprezo e orgulho (Darwin, 1872). Embora existam outras emoções, incluímos essas que suprem as necessidades analíticas. Os quadros estão divididos em função de quem estuda os casos. Os movimentos verificados na coluna direita, isolados e/ou em combinação, constituem o símbolo que designa determinada emoção:

Quadro 1 - Diagramas Faciais de Darwin (1872)

\begin{tabular}{|c|c|}
\hline $\begin{array}{l}\text { Reflexão/ } \\
\text { meditação }\end{array}$ & - Expressão vaga dos olhos \\
\hline Desdém/desprezo & $\begin{array}{l}\text { - Fechamento parcial das pálpebras; } \\
\text { - Afastar os olhos ou o corpo do interlocutor; } \\
\text { - Nariz ligeiramente levantado ou contraído; } \\
\text { - Elevação do lábio superior; } \\
\text { - Enrugamento do nariz. }\end{array}$ \\
\hline Orgulho & $\begin{array}{l}\text { - Cabeça ereta; } \\
\text { - Pálpebras abaixadas. }\end{array}$ \\
\hline
\end{tabular}

Fonte: Elaborada pela autora com base em Darwin (1872)

Quadro 2 - Diagramas Faciais de Ekman e Friesen (2003)

\begin{tabular}{|l|l|}
\hline Surpresa & $\bullet$ Sobrancelhas levantadas; \\
& • Olhos bem abertos, com as pálpebras inferiores \\
& relaxadas e as pálpebras superiores levantadas; \\
& $\bullet$ Longas rugas horizontais na testa; \\
& $\bullet$ Queixo caído.
\end{tabular}

Cad. Trad., Florianópolis, v. 39, no 3, p. 132-155, set-dez, 2019. 


\begin{tabular}{|c|c|}
\hline Nojo & $\begin{array}{l}\text { - Pele pálida, suada; } \\
\text { - Respiração rápida; } \\
\text { - Sobrancelhas erguidas e juntas; } \\
\text { - Olhos abertos e a pálpebra inferior tensa; } \\
\text { - Boca aberta, lábios tensos e repuxados para trás } \\
\text { - Testa imóvel }\end{array}$ \\
\hline Presunção & $\begin{array}{l}\text { - Mistura sinais rápidos de felicidade e desprezo: } \\
\text { - Levantamento unilateral do lábio superior } \\
\text { acompanhado de um sorriso; } \\
\text { - Boca fechada e lábios estreitados, bochechas } \\
\text { levantadas e pálpebras inferiores enrugadas devido à } \\
\text { felicidade contida. }\end{array}$ \\
\hline
\end{tabular}

Fonte: Elaborada pela autora com base em Ekman e Friesen (2003)

\section{Analisando o papel do plano-frase sobre as legendas das falas de Lady Violet}

Dos cinco episódios selecionados da $1 \mathrm{~T}$ de $D A$, selecionamos oito cenas, que resultaram em 11 passagens analisadas e, para este artigo, trazemos quatro dessas passagens.

A primeira passagem a ser destacada foi retirada do Episódio 01, quando Lady Violet procura recrutar a sua nora, Cora, para contemplar as alternativas que poderiam prevenir a propriedade e a fortuna da família de irem para Matthew Crawley. Apresentamos no quadro abaixo o diálogo e, em seguida, imagens capturadas da cena:

\section{Quadro S01E01}

\begin{tabular}{|l|l|l|}
\hline LINHA & FALA ORIGINAL & LEGENDAS \\
\hline 1.1.L44 & $\begin{array}{l}\text { Cora: } \text { Are we to be friends, } \\
\text { then? (0:18:36) }\end{array}$ & $\begin{array}{l}\text { Devemos ser amigas, } \\
\text { então? }\end{array}$ \\
\hline 1.1.L45 & $\begin{array}{l}\text { Lady Violet: We are allies, my } \\
\text { dear... (0:18:42) }\end{array}$ & $\begin{array}{l}\text { Somos aliadas, minha } \\
\text { cara... }\end{array}$ \\
\hline
\end{tabular}

Cad. Trad., Florianópolis, v. 39, no 3, p. 132-155, set-dez, 2019. 


\begin{tabular}{|l|l|l|}
\hline 1.1.L46 & $\begin{array}{l}\text { Lady Violet: ... which can be } \\
\text { a good deal more effective. } \\
(0: 18: 45)\end{array}$ & $\begin{array}{l}\text { o que pode ser um } \\
\text { negócio mais eficaz. }\end{array}$ \\
\hline
\end{tabular}

Fonte: Elaborado pela autora com base em Downton Abbey (2010).

Na série, Cora deseja ser aceita pela sogra, por isso ela produz a fala na linha 1.1.L44, ao que a Condessa Viúva responde de forma a contradizer as expectativas da nora nas linhas 1.1.L45 e 1.1L46. A tradução do enunciado contido nas linhas 1.1.L45 e 1.1L46 foi selecionado para análise porque a expressão "good deal" foi, ao mesmo tempo, suprimida e inspirou o produto final das legendas, acreditamos que uma explicação para isso se encontre no eixo EFA nos planos-frase abaixo.

A expressão "good deal" é uma expressão idiomática que equivale a "muito" 3 . Ou seja, sua função no enunciado é modificar, pela adição de intensidade, a expressão "more effective" (mais eficaz). "Good" equivale a "bom" e "deal", a "trato" ou "acordo", ou ainda "transação", o que pode evocar ideias relacionadas ao mundo de negócios. Assim sendo, antes de atribuirmos a inserção do vocábulo "negócio" no produto da legenda na linha 1.1.L46 a um erro ingênuo, precisamos cogitar a possibilidade de que haja um fato motivador para a sua presença.

${ }^{3}$ A good deal / A great deal. Cambridge Dictionary. Disponível em: < https:// dictionary.cambridge.org/pt/dicionario/ingles-frances/a-good-deal-a-great-deal > Acesso em: 14 de jul. de 2018.

Cad. Trad., Florianópolis, v. 39, no 3, p. 132-155, set-dez, 2019. 
Imagem 2 - Lady Violet prepara-se para responder Cora

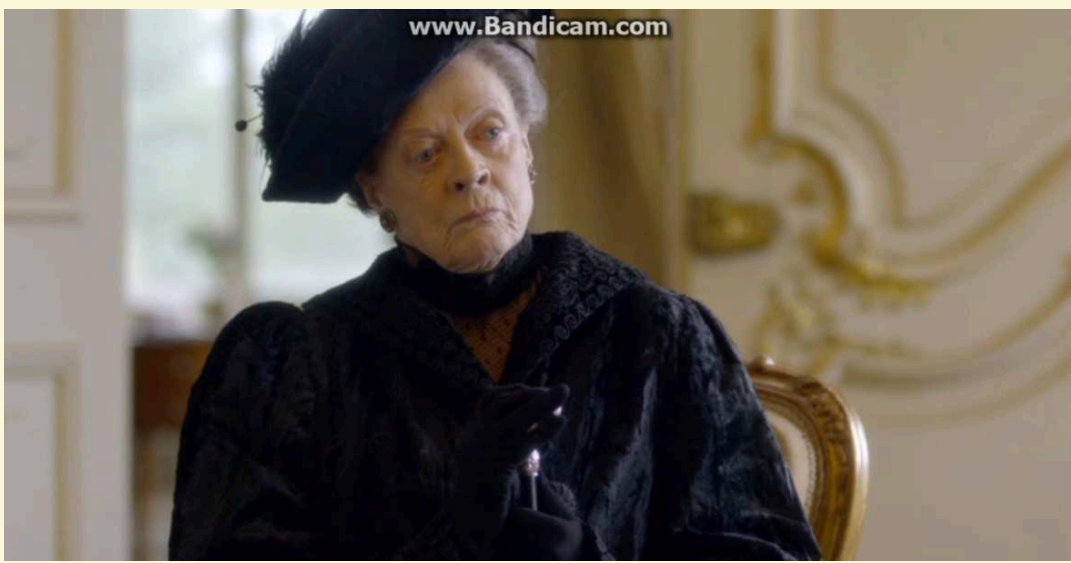

Fonte: Downton Abbey. Direção de Brian Percival. Roteiro: Julian Fellowes. Londres: Carnival Film \& Television, 2010. 3 DVDs (378 min.), DVD, son., color. Legendado. Série 1.

\section{Imagem 1.1.L46}

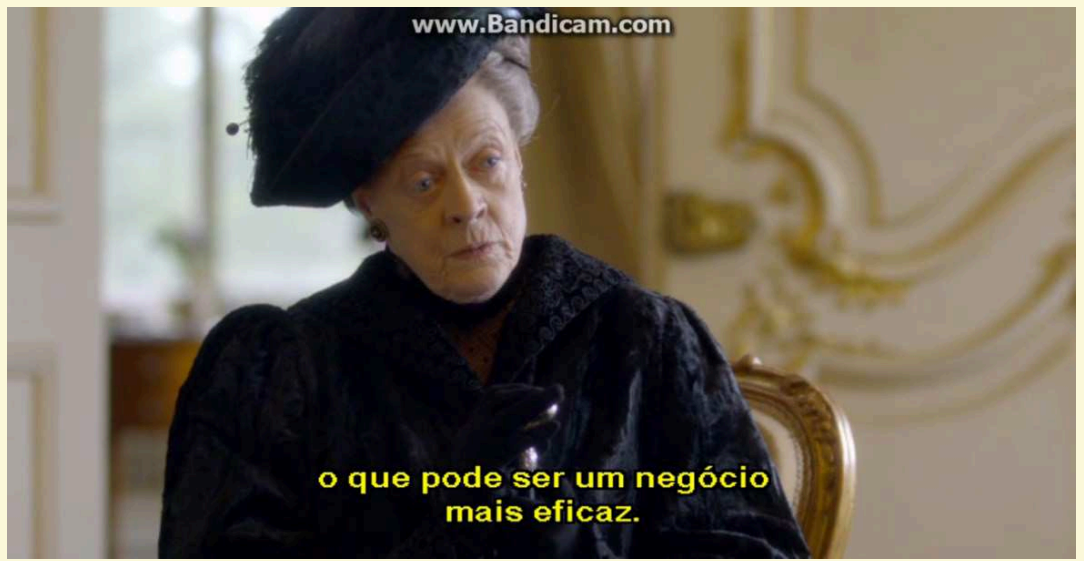

Fonte: Downton Abbey. Direção de Brian Percival. Roteiro: Julian Fellowes. Londres: Carnival Film \& Television, 2010. 3 DVDs (378 min.), DVD, son., color. Legendado. Série 1. 
Estudando o eixo EFA nos planos-frase acima, vemos a atitude da personagem Lady Violet em relação à asserção de Cora: notamos um fechamento parcial das pálpebras da atriz na Imagem 2, bem como um afastamento da cabeça da atriz em direção oposta à posição de Cora, o nariz ligeiramente levantado e a elevação do lábio superior, embora ela mantenha os lábios cerrados. Esses sinais rápidos formam o símbolo para desdém ou desprezo (DARWIN, 1872). Em sua fala, Lady Violet implica indiretamente que ela e a nora não serão amigas.

Dessa forma, acreditamos que o eixo EFA influenciou os processos lógicos mentais do legendador e sua tomada de decisão se baseou não só no que é dito, mas no que não é dito explicitamente, sendo compreensível apenas pela tradução intersemiótica da linguagem não-verbal empregada pela atriz que interpreta Lady Violet, que demonstra não estar disposta a diminuir o distanciamento afetivo entre ela e sua nora e, assim, estimulou o uso do substantivo "negócio" para caracterizar a relação estabelecida entre as duas.

Prosseguiremos agora para o diálogo que acontece entre Lady Violet e Cora no Episódio 06. Nele, as personagens discutem como abafar os fatos que poderiam levar à ruína da reputação da filha primogênita dos Crawley, que teve um caso com um funcionário da embaixada turca quando este visitou a residência da família - fato que se tornou conhecido do embaixador turco. Lady Violet alega que, pela escassez de visitantes à embaixada turca, é possível que o segredo delas não esteja em sério risco. Cora Crawley, porém, lembra à sogra que basta uma pessoa saber para que a situação saia de controle. Diante dessa advertência, a Condessa Viúva produz o seguinte enunciado:

Quadro S1E06 - Fragmento 2

\begin{tabular}{|l|l|l|}
\hline LINHA & FALA ORIGINAL & LEGENDAS \\
\hline 1.6.L18 & $\begin{array}{l}\text { Lady Violet: I mean, it just } \\
\text { can't be helped. }(00: 46: 10)\end{array}$ & Isso não pode ser evitado. \\
\hline
\end{tabular}

Cad. Trad., Florianópolis, v. 39, no 3, p. 132-155, set-dez, 2019. 


\begin{tabular}{|l|l|l|}
\hline 1.6.L19 & $\begin{array}{l}\text { Lady Violet: We can't } \\
\text { have'em assassinated. } \\
(00: 46: 13)\end{array}$ & $\begin{array}{l}\text { Por certo, não podemos } \\
\text { assassiná-las. }\end{array}$ \\
\hline 1.6.L20 & $\begin{array}{l}\text { Lady Violet: }[. . .] \text { I suppose. } \\
\text { (00:46:13) }\end{array}$ & Eu acho. \\
\hline
\end{tabular}

Fonte: Elaborado pela autora com base em Downton Abbey (2010).

\section{Imagem 1.6.L20}

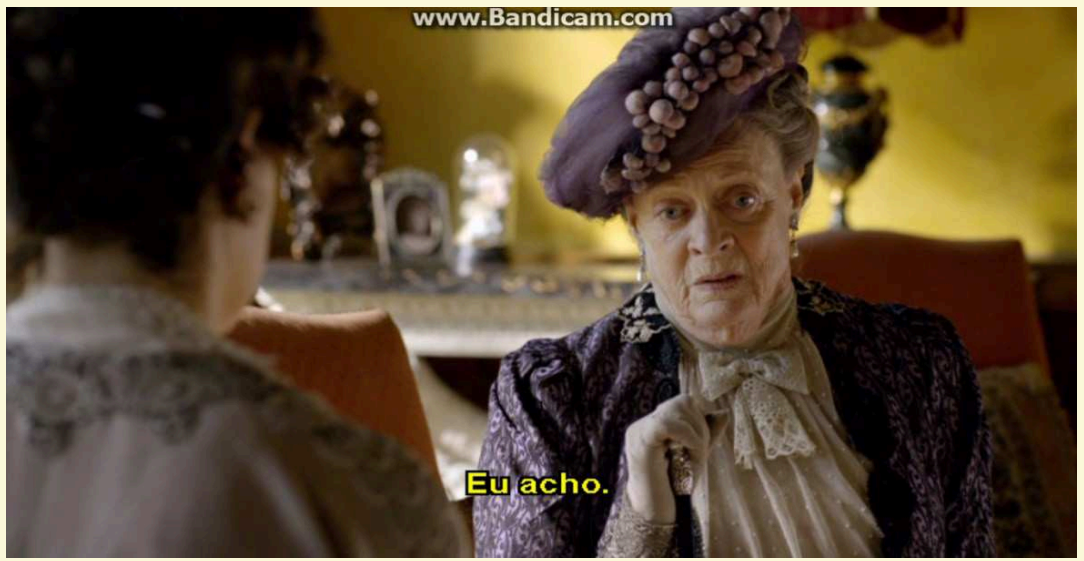

Fonte: Downton Abbey. Direção de Brian Percival. Roteiro: Julian Fellowes. Londres: Carnival Film \& Television, 2010. 3 DVDs (378 min.), DVD, son., color. Legendado. Série 1.

Observamos que o tradutor suprimiu a expressão "I mean", utilizando a estratégia de redução de elementos na legenda (Georgakopoulou, 2009). Porém, na linha seguinte, o legendador adiciona a expressão "Por certo", cujo equivalente não se encontra na fala original. Uma das possíveis razões motivadoras dessa adição pode ser encontrada logo em seguida: quando Lady Violet contradiz com sua afirmação na linha 1.6.L19 ao dizer "I suppose" na linha 1.6.20. A afirmação da linha 1.6.19 é contradita tanto no nível verbal quanto no nível não-verbal, pois analisando a Imagem 1.6.L20 encontramos a expressão vaga nos olhos da atriz, que como proposto 
por Darwin (1872), é um sinal de reflexão/meditação. Ao assistir à cena, interpretamos a expressão de Lady Violet como evidência de que ela deixa implícita a cogitação de um plano assassino para prevenir as pessoas de entrarem em contato com o ministro turco.

Por meio dessa fala e da sua expressão facial, Lady Violet demonstra sua natureza irônica, que o tradutor parece ter levado em consideração ao enfatizar a fala na linha 1.6.L19 pela inclusão da locução adverbial "por certo", que garantiria uma quebra de expectativas do público ainda maior ao final do enunciado. Assim, verificamos um efeito retroativo do eixo EFA no plano-frase da Imagem 1.6.L20 sobre a linha 1.6.L19. Desse modo, o legendador pode ter pensado na progressão dramática e, também, na caracterização da personagem, realçando as características que a distinguem. Assim, legenda na linha 1.6.L19 dá indícios de ter sido influenciada pelo plano-frase.

O diálogo abaixo também se dá no último episódio da 1T. A família está reunida para jantar e Lady Violet tenta iniciar um diálogo com Isobel, mãe de Matthew, que não parece engajada na troca entre as duas em virtude da sua desconfiança quanto à influência de Lady Violet sobre a decisão (ou a falta dessa) de Mary em relação ao pedido de casamento de Matthew.

\section{Quadro S01E07.1}

\begin{tabular}{|l|l|l|}
\hline LINHA & FALA ORIGINAL & LEGENDAS \\
\hline 1.7.2.L01 & $\begin{array}{l}\text { Lady Violet: First } \\
\text { electricity, now } \\
\text { telephones. (00:34:58) }\end{array}$ & $\begin{array}{l}\text { Primeiro eletricidade, agora } \\
\text { telefones. }\end{array}$ \\
\hline 1.7.2.L02 & $\begin{array}{l}\text { Lady Violet: Sometimes } \\
\text { Ifeel as if I were living } \\
\text { in an H.G. Wells novel. } \\
\text { (O0:35:00) }\end{array}$ & $\begin{array}{l}\text { Às vezes, me sinto como } \\
\text { se estivesse vivendo em um } \\
\text { romance de H.G. Wells. }\end{array}$ \\
\hline 1.7.2.L03 & $\begin{array}{l}\text { Lady Violet: But the } \\
\text { young are all so calm } \\
\text { about change, aren't } \\
\text { they? (00:35:06) }\end{array}$ & $\begin{array}{l}\text { Mas os jovens ficam tão } \\
\text { calmos com todas estas } \\
\text { mudanças, não é? }\end{array}$ \\
\hline
\end{tabular}

Cad. Trad., Florianópolis, v. 39, no 3, p. 132-155, set-dez, 2019. 


\begin{tabular}{|c|c|c|}
\hline 1.7.2.L04 & $\begin{array}{l}\text { Lady Violet: Look at } \\
\text { Matthew. I do admire } \\
\text { him. (00:35:12) }\end{array}$ & $\begin{array}{l}\text { Veja Matthew. Realmente o } \\
\text { admiro. }\end{array}$ \\
\hline 1.7.2.L05 & $\begin{array}{l}\text { Isobel: Do you? } \\
(00: 35: 16)\end{array}$ & É mesmo? \\
\hline 1.7.2.L06 & $\begin{array}{l}\text { Lady Violet: What have } \\
\text { I done wrong now? } \\
(00: 35: 20)\end{array}$ & O que fiz de errado agora? \\
\hline 1.7.2.L07 & $\begin{array}{l}\text { Isobel: Oh, please! } \\
(00: 35: 21)\end{array}$ & Por favor. \\
\hline 1.7.2.L08 & $\begin{array}{l}\text { Isobel: Don't pretend } \\
\text { Mary's sudden } \\
\text { reluctance ... (00:35:23) }\end{array}$ & $\begin{array}{l}\text { Não finja que a súbita } \\
\text { relutância de Mary... }\end{array}$ \\
\hline 1.7.2.L09 & $\begin{array}{l}\text { Isobel: ... can't be } \\
\text { traced back to you. ? } \\
(00: 35: 26)\end{array}$ & não tem relação com você. \\
\hline 1.7.2.L10 & $\begin{array}{l}\text { Lady Violet: Well, } \\
\text { I shall pretend it. I } \\
\text { told her to take him. } \\
(00: 35: 28)\end{array}$ & $\begin{array}{l}\text { E não tem mesmo. Eu disse a } \\
\text { ela que ficasse com ele. }\end{array}$ \\
\hline 1.7.2.L11 & $\begin{array}{l}\text { Lady Violet: Your } \\
\text { quarrel is with my } \\
\text { daughter Rosamund, not } \\
\text { me. (00:35:32) }\end{array}$ & $\begin{array}{l}\text { Tem que brigar com minha } \\
\text { filha Rosamund, não comigo. }\end{array}$ \\
\hline 1.7.2.L12 & $\begin{array}{l}\text { Lady Violet: So, put that } \\
\text { in your pipe and smoke } \\
\text { it. (00:35:36) }\end{array}$ & Essa você vai ter que engolir! \\
\hline
\end{tabular}

Fonte: Elaborado pela autora com base em Downton Abbey (2010).

Na primeira fala de Lady Violet, destacaremos as legendas na linha 1.7.2.L02. Constatamos que o legendador optou por uma tradução literal da fala. H.G.Wells foi um autor britânico que viveu entre 1866 e 1946, seu principal legado é no gênero de ficção científica, incluindo a novela $A$ Máquina do Tempo (1895). O gênero relaciona ciência e tecnologia e seu impacto em uma socie- 
dade ou cultura em um quadro temporal no futuro. A fala de Lady Violet é direcionada a Isobel e pressupõe que ela conheça o autor e o seu trabalho. Como H.G. Wells é um notório escritor britânico, é plausível esperar que parte da audiência nativa de $D A$ o conheça. Porém, fora do território britânico, talvez a população que reconheça o nome de Wells e seu trabalho seja mais limitado.

\section{Imagem 1.7.2. L02}

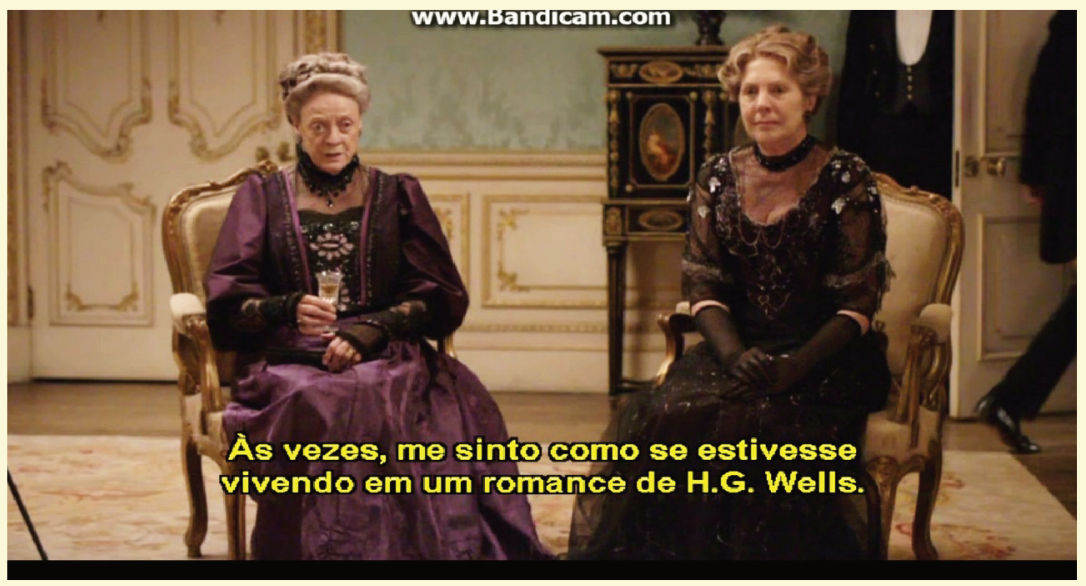

Fonte: Downton Abbey. Direção de Brian Percival. Roteiro: Julian Fellowes. Londres: Carnival Film \& Television, 2010. 3 DVDs (378 min.), DVD, son., color. Legendado. Série 1.

Lady Violet implica que as novas tecnologias que estão chegando a $D A$ a fazem se sentir deslocada temporalmente para o futuro. Uma proposta de legenda menos literal, mas que tornaria o significado de Lady Violet acessível para um público maior poderia ser: "Às vezes, sinto como se vivesse em um romance de ficção científica”.

Observando o plano-frase que corresponde à fala (Imagem 1.7.2. L02) e consultando o eixo EFA, verificamos o símbolo-expressão-facial de surpresa marcada pelo diagrama facial formado pelos sinais rápidos de sobrancelhas levantadas, olhos bem 
abertos, intensificação das rugas horizontais na testa da atriz e o queixo levemente caído.

É possível que, para algumas audiências, a referida imagem realize um efeito compensatório acerca do que a atriz implica em sua fala, especialmente à luz das falas na linha que precede e na linha que sucede a asserção da personagem na linha analisada. Dessa forma, a imagem se converte em um input mais relevante do que as legendas para a interpretação do desconforto de Lady Violet diante de todas as mudanças tecnológicas que estão chegando ao seu meio.

Mais adiante no mesmo diálogo, destacamos o enunciado que começa na linha 1.7.2.L10 e termina na linha 1.7.2.L12. Como pode ser verificado no quadro acima, na linha 1.7.2.L10, a tradução literal para "Well, I shall pretend it" seria "Bem, eu fingirei”. Essa resposta à acusação de Isobel na linha 1.7.2.L09 é a declaração de inocência de Lady Violet. Nas legendas, o legendador optou por propor uma declaração de inocência explícita para as legendas com a asserção mais direta "E não tem mesmo.", que nega de forma veemente aquilo que está sendo dito sobre ela - o que é marcado, principalmente, pelo uso do vocábulo "mesmo" como advérbio significando "de fato", "verdadeiramente", "realmente". A surpresa da personagem quanto a essa acusação da qual ela é inocente é reforçada pelo planofrase que acompanha a fala. Na Imagem 1.7.2.L10, vemos o símbolo-expressão-facial de surpresa: 


\section{Imagem 1.7.2.L10}

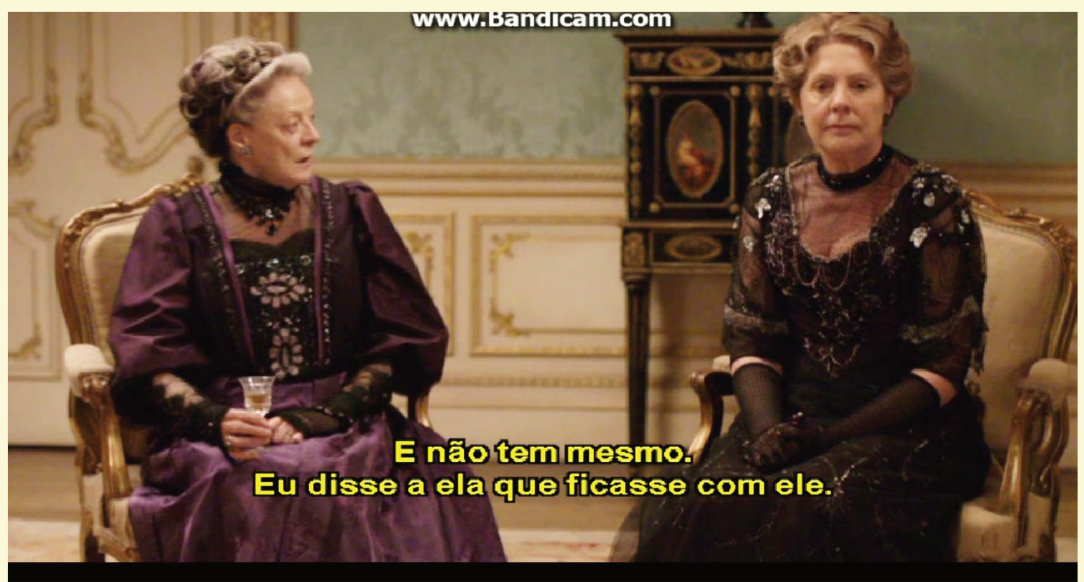

Fonte: Downton Abbey. Direção de Brian Percival. Roteiro: Julian Fellowes. Londres: Carnival Film \& Television, 2010. 3 DVDs (378 min.), DVD, son., color. Legendado. Série 1.

Na linha 1.7.2.L11, Lady Violet explica quem, de fato, deu os conselhos que abalaram a confiança de Mary Crawley na resposta que ela deveria oferecer a Matthew e completa seu enunciado com a fala na linha 1.7.2.L12. A expressão idiomática "put that in your pipe and smoke it" (literalmente: coloque isso no seu cachimbo e fume) não encontra um correspondente literal na língua portuguesa do Brasil. Portanto, para traduzir essa expressão idiomática é preciso, primeiro, elaborar uma implicatura que revele o objetivo do remetente. No caso "put that in your pipe and smoke it" é uma forma antiquada de dizer a alguém que ele/a terá que aceitar o que o interlocutor disse mesmo que isso o/a desagrade ${ }^{4}$. Para legendar a fala em questão, o legendador escolheu uma expressão comumente empregada no Brasil, também utilizada como recurso de

\footnotetext{
${ }^{4}$ Put/stick that in your pipe and smoke it!. Cambridge Dictionary. Disponível em: $<$ https://dictionary.cambridge.org/pt/dicionario/ingles/put-stick-that-in-yourpipe-and-smoke-it > Acesso em: 18 de jul. de 2018.
} 
contra-ataque, que significa que a pessoa deverá aceitar e/ou calar uma verdade ou uma ofensa ${ }^{5}$.

A seguir, apresentamos a Imagem 1.7.2.L12, que representa o momento em que a atriz profere a fala enquanto afasta o corpo e o rosto da sua interlocutora em expressão de desdém à afirmação infundada da última e corrobora a implicatura, tanto da fala original quanto da legenda.

\section{Imagem 1.7.2.L12}

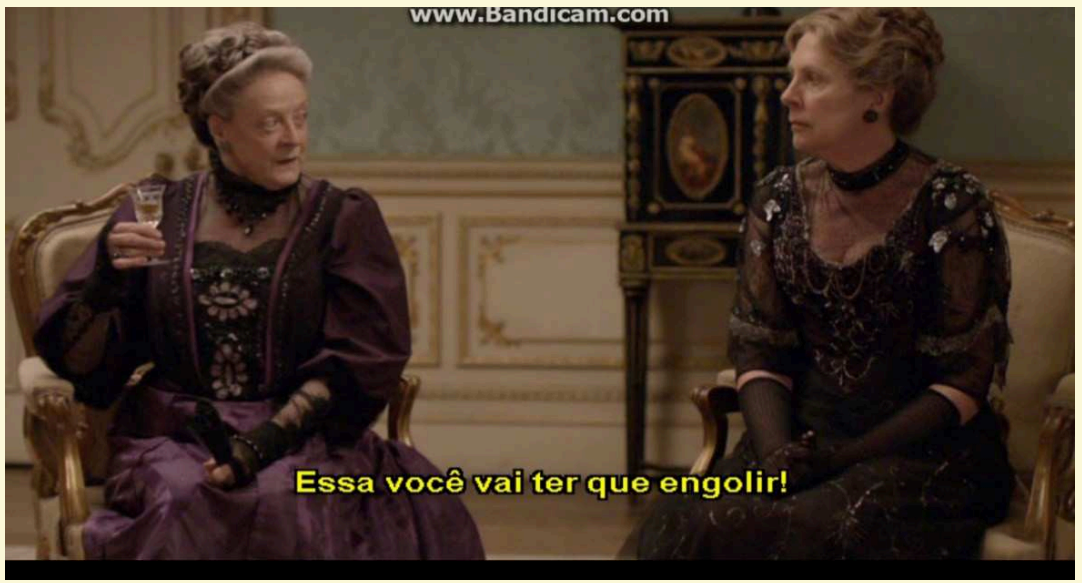

Fonte: Downton Abbey. Direção de Brian Percival. Roteiro: Julian Fellowes. Londres: Carnival Film \& Television, 2010. 3 DVDs (378 min.), DVD, son., color. Legendado. Série 1.

\section{Considerações finais}

No decorrer deste artigo, buscamos atender ao objetivo de investigar a influência da TI para o processo de legendagem de um produto, tomando como objeto de estudo a personagem Lady Vio-

${ }^{5}$ Engolir. Léxico - Dicionário de Português Online. Disponível em: < https:// www.lexico.pt/engolir/> Acesso em: 18 de jul. de 2018. 
let em $D A$. A instigação para desenvolver o estudo foi o fato de que, apesar de a revolução na área da comunicação ter desalojado a linguagem verbal (oral ou escrita) da sua outrora centralidade, ainda estamos carentes de uma compreensão da linguagem semiótica, dentro dos Estudos da Tradução, voltados para no campo do Audiovisual se pensar o não-verbal imagético.

Como esclarecemos anteriormente, Skuggevik (2009) pontua que ao legendador é necessária a compreensão da dimensão emocional e psicológica de uma cena, mas não aprofunda como essa compreensão é feita. No percorrer deste estudo, empenhamo-nos por demonstrar como a apreensão da dimensão emocional e psicológica de uma cena se dá pela leitura do não-verbal em associação ao verbal. Porém, ressaltamos que essa leitura do não-verbal não é universal ou inata ao ser humano (Ekman; Friesen, 2003), ora sim uma habilidade a ser trabalhada e desenvolvida e que pelo desenvolvimento dessa habilidade derivam-se decisões pragmáticas de tradução audiovisual.

Ao analisar a dimensão psicológica da cena, observamos como a linguagem não-verbal é um elemento com o qual o legendador deve trabalhar para manter a integridade estilística da obra, de forma que a legenda se torne parte do panorama semiótico da produção e seja, de fato, "invisível". Verificamos como a imagem em um produto audiovisual reflete sobre o produto da legenda pela influência, compensação ou ainda complementação. Por isso, ressaltamos que a competência em TI não depende apenas da leitura imagética, fazendo parte de um entrecruzamento intrínseco entre o fato verbal e não-verbal. Tal intercruzamento facilita o trabalho do legendador, uma vez que esse já deve observar numerosas limitações técnicas, linguísticas e textuais.

Considerando a recorrência da temática da tricotomia neste estudo, o interesse está voltado para a intersecção entre (1) construção imagética do plano-frase, (2) legendas e (3) linguagem não-verbal paralinguística, sendo esses pontos de grande valia para a compreensão dos diversos elementos que concorrem e/ou se envolvem para manter a atenção do telespectador na progressão dramática. Já que, como 
observamos, a experiência bifurcada de consumir produtos fílmicos legendados detém essa característica em duas instâncias: primeiro, pela exposição simultânea ao oral e ao escrito em duas línguas diversas; segundo, pela exposição ao elemento não-verbal e verbal em tela. A verdadeira amenização dos efeitos dessas bifurcações só pode se dar por uma legenda que acomoda esses três elementos.

Esse ponto demonstra os limites deste estudo e foi elencado para, possivelmente, instigar novas investigações que possam vir a complementar, aprofundar ou continuar o ponto de análise que iniciamos aqui. Registramos, assim, o convite para outros que, seguindo nossas sugestões ou identificando diferentes pontos de investigação, possam juntar-se a nós no empreendimento de aprender a pensar o que vemos, em um exercício de observação que nos leve a questionar aquilo que pode nos parecer transparente e a vislumbrar como a técnica envolvida na área de legendagem pode lucrar do reconhecimento das nossas limitações.

\section{Referências}

Betz, Mark. Beyond the Subtitle: Remapping European Art Cinema. London: University of Minnesota Press, 2009.

Cintas, Jorge Díaz; Anderman, Gunilla. Audiovisual Translation: Language Transfer on Screen. New York: Palgrave Macmillan, 2009.

Cintas, Jorge Díaz; Remael, Aline. Audiovisual Translation: Subtitling. Nova York: Routledge, 2014.

Darwin, Charles. The Expression of the Emotions in Man and Animals. London: John Murray, 1872. 
Ekman, Paul; Friesen, Wallace V. Unmasking The Face. Los Altos: Malor Books, 2009.

Frías, José Yuste. Leer e interpretar la imagen para traducer. In: Trabalhos de Linguística Aplicada. n. 50.2. jul/dez. 2011. p. 257-280. Disponível em: < http:// www.scielo.br/scielo.php?pid $=$ S0103-18132011000200003\&script $=$ sci arttext > Acesso em: 09 jan. 2017

Georgakopoulou, Panayota. Subtitling for the DVD Industry. In: Cintas, Jorge Díaz; Anderman, Gunilla (Org.). Audiovisual Translation Language Transfer on Screen. New York: Palgrave Macmillan, 2009.

Gorovitz, Sabine. Os Labirintos da Tradução. Brasília: Editora Universidade de Brasília, 2015.

Jakobson, Roman. On linguistic aspects of translation. In: Vennuti, L. (org.) The Translation Studies Reader. London: Routledge, 2000.

Metz, Christian. A Significação no Cinema. Tradução de Jean-Claude Bernadet. São Paulo: Perspectiva, 2014.

Pierce, Charles Sanders. Semiótica. Tradução de José Teixeira Coelho Neto. São Paulo: Perspectiva, 2015.

Pignatari, Décio. Semiótica e Literatura. $6^{\text {a }}$ ed. Cotia, SP: Ateliê Editorial, 2004.

Plaza, Julio. Tradução Intersemiótica. 2a ed. São Paulo: Perspectiva, 2013.

Poyatos, Fernando. Language and Nonverbal Systems in the Structure of Faceto-Face Interaction. Language \& Communication. Vol. 3. N.2, P. 129-140. Pergamon Press: Grã-Bretanha, 1983. Disponível em: < https://e-edu.nbu.bg/ pluginfile.php/419684/mod_resource/content/1/Poyatos \%20-\%20Language \%20 and \%20NVSystems \%20of\% 20Communication.pdf > . Acesso em: 01 abr. 2017

Shohat, Ella; Stam, Robert. The Cinema after Babel: Language, Difference, Power. In: Shohat, Ella. Taboo Memories, Diasporic Voices. Durham/London: Duke University Press, 2006. P. 106-138. 
Skuggevik, Erik. Audiovisual Translation Language Transfer on Screen Teaching Screen Translation: The Role of Pragmatics in Subtitling. In: Cintas, Jorge Díaz; Anderman, Gunilla (Org.) Audiovisual Translation: Language Transfer on Screen. Nova York: Palgrave Macmillan, 2009.

Weil, Pierre. TOMPAKOW, Roland. O Corpo Fala: A Linguagem Silenciosa da Comunicação Não-verbal. Petrópolis, Vozes, 1986.

Recebido em: 10/02/2019 Aceito em: 01/07/2019 Publicado em: Setembro de 2019

Rossana Luna. E-mail: rssnluna@gmail.com ORCID: https://orcid.org/0000-0003-3355-7916 Sinara de Oliveira Branco. E-mail: sinarabranco@gmail.com ORCID: https://orcid.org/0000-0003-2739-2254 